\begin{tabular}{|l|l|l}
\hline Received : November 2020 & Accepted: December 2020 & Published : January 2021 \\
\hline
\end{tabular}

\title{
Destination Branding Pantai Blimbingsari sebagai Sentra Kuliner Ikan Bakar di Kabupaten Banyuwangi
}

\author{
Adetiya Prananda Putra ${ }^{1 *}$, Ayu Purwaningtyas², Tri Ajeng Rizki Ayu Pertiwi ${ }^{3}$ \\ 1,2,3 Program Studi Manajemen Bisnis Pariwisata, Politeknik Negeri Banyuwangi
}

*Email: adit.prananda@ poliwangi.ac.id

\begin{abstract}
Blimbingsari beach is one of a kind of Banyuwangi's beach that have a high potential on grilled fish special culinary aspect This beach became the pioneer of Banyuwangi's very first seafood and grilled fish restaurant with 'lesehan' type, and that was the brand was formed ever since. Thus also makes the image of Blimbingsari skyrocket and built perspective of tourists for years and the paradigm brings many people to come and try the dish by themselves. However, Blimbingsari beach has not optimalize the brand identity they have and has no tagline or destination icon to increase the branding yet. The main purpose of this research is to formulate of priority strategies of Blimbingsari destination branding as a grilled fish culinary center which lies in Banyuwangi.This research is using qualitative descriptive with SWOT analysis and AHP for making desicion in a path of top priority strategies. And the result itself, shows that the culinary potential has been being built by brand and long-journey tourist perspective, the taste of the grilled fish itself, best price dishes and comfortable ambiance. The highest strenght factor owned Blimbingsari beach is having a strategic location, the main weakness factor is inadequate food utensils. The major opportunity of factor is the sinergy between to communities to increase regional profit and the main threat factor is the emergence of new competitors. In addition, this research also produced five priority strategies.
\end{abstract}

Keywords: Blimbingsari beach, destination branding, grilled fish culinary

\begin{abstract}
Abstrak
Pantai Blimbingsari merupakan salah satu pantai di Kabupaten Banyuwangi yang memiliki potensi kuliner yaitu ikan bakar. Citra kuliner ini terbentuk karena Pantai Blimbingsari menjadi pionir warung dengan sajian ikan bakar yang mengusung tema lesehan di Banyuwangi. Hal ini menjadikan citra kuliner Pantai Blimbingsari melejit dan membangun perspektif wisatawan selama bertahun-tahun. Namun, Pantai Blimbingsari belum memaksimalkan brand identity yang dimiliki seperti belum ada ikon dan tagline destinasi untuk meningkatkan branding-nya. Tujuan utama penelitian ini adalah merumuskan strategi prioritas destination branding Pantai Blimbingsari sebagai sentra kuliner ikan bakar di Kabupaten Banyuwangi. Metode penelitian yang digunakan adalah deskriptif kualitatif dengan teknik analisis SWOT serta AHP sebagai metode pengambilan keputusan. Hasil dari penelitian ini menunjukan potensi kuliner ikan bakar meliputi citra dan perspektif wisatawan yang telah terbentuk sejak lama, cita rasa yang lezat, harga yang terjangkau serta suasananya yang nyaman. Faktor kekuatan tertingginya adalah lokasinya yang strategis dan faktor kelemahan utamanya adalah penggunaan alat-alat saji yang kurang layak. Serta faktor peluang tertingginya adalah sinergi antar masyarakat untuk meningkatkan profit daerah dan ancaman utamanya adalah munculnya kompetitor baru. Selain itu, penelitian ini juga menghasilkan 5 strategi prioritas.
\end{abstract}

Kata kunci: destination branding, kuliner ikan bakar, pantai Blimbingsari 


\section{Pendahuluan}

Sektor pariwisata terus mengalami perkembangan secara signifikan dari tahun ke tahun. Perkembangan ini menciptakan banyaknya industri-industri baru dan pengembangan destinasidestinasi yang berdampak positif bagi sejumlah daerah, khususnya Indonesia. Menurut Kementrian Pariwisata (2017), pariwisata menjadi salah satu sektor prioritas dalam pembangunan Indonesia. Hal ini diperkuat oleh data dari Badan Pusat Statistik dan Kementrian Perindustrian (2017) yang menyebutkan bahwa sektor pariwisata menduduki urutan kedua dalam peringkat 10 besar penyumbang terbesar devisa negara setelah hasil ekspor kelapa sawit yaitu sebesar 190 triliun rupiah. Hal ini menunjukan bahwa pariwisata merupakan sektor yang perlu mendapat perhatian lebih dari pemerintah agar devisa negara dapat terus mengalami peningkatan dan ekonomi masyarakat dapat terus bertumbuh seiring dengan perkembangan pariwisata. Indonesia sendiri memiliki banyak sekali tempat-tempat yang sangat potensial untuk dikembangkan sektor pariwisatanya, baik yang bersifat alam, budaya dan kultural maupun wisata buatan. Salah satu daerah dengan potensi pariwisata tersebut adalah Kabupaten Banyuwangi.

Kabupaten Banyuwangi merupakan kabupaten yang berlokasi di ujung timur Pulau Jawa, tepatnya di kawasan Tapal Kuda. Terletak pada $7^{\circ} 43^{\prime}-8^{\circ} 46^{\prime}$ Lintang Selatan dan $113^{\circ} 53^{\prime}-114^{\circ} 38^{\prime}$ Bujur Timur, Banyuwangi termasuk dalam jajaran kabupaten yang memiliki garis pantai terpanjang di Pulau Jawa yang mencapai 175,8 meter. Selain kaya dengan destinasi wisata alam yang eksotis, Banyuwangi juga dianugerahi dengan suburnya wisata budaya dan wisata kuliner yang hingga saat ini menjadi potensi utama dalam pengembangan sektor pariwisatanya.

Perkembangan sektor pariwisata yang dirancang oleh Kabupaten Banyuwangi terus mengalami pembenahan dari waktu ke waktu. Beberapa contoh perkembangan yang telah dilakukan pemerintah Banyuwangi telah membuahkan hasil yang positif. Beberapa prestasi telah berhasil diraih Banyuwangi, baik dalam kancah Nasional maupun Internasional. Prestasi- prestasi tersebut misalnya, penghargaan desa terbaik untuk daya tarik wisata yang dimenangkan oleh Desa Kemiren dalam Anugerah Wisata Jawa Timur tahun 2019, memenangkan penghargaan pariwisata dalam ASEAN Tourism Standard Award di tahun 2018 hingga penetapan Banyuwangi sebagai kawasan Geological Park atau Geopark Nasional pada tahun 2018 untuk Blue Fire di Gunung Ijen, Pulau Merah dan Taman Nasional Alas Purwo. Pada tahun 2017, Banyuwangi juga terpilih dalam 10 destination branding yang dipilih oleh Kementrian Pariwisata Republik Indonesia untuk memperkuat citra pariwisata Indonesia di kancah internasional dengan tajuk Wonderful Indonesia.

Potensi-potensi wisata yang dimiliki kabupaten Banyuwangi masih banyak yang belum tergarap dengan maksimal seperti Air Terjun Tumpak Sewu, Gunung Ranti, Pantai Cacalan, Situs Rowo Bayu Songgon, Pantai Cemara, Pantai Poncomoyo, Pantai Blimbingsari dan masih banyak yang lainnya. Meski belum teroptimalkan pengembangannya, masing-masing destinasi tersebut memiliki potensi yang unik serta memiliki ciri khas tersendiri. Salah satunya adalah Pantai Blimbingsari.

Pantai Blimbingsari terletak di Kecamatan Blimbingsari, berjarak sekitar 23 kilometer dari pusat Kota Banyuwangi dan sekitar 1 kilometer dari Bandar Udara Banyuwangi. Aksesibilitas yang terdapat di pantai ini juga tergolong mudah dan layak karena jalan masuk menuju bibir pantai telah teraspal dengan baik. Lokasinya terbilang strategis karena berdekatan dengan gerbang masuk Banyuwangi melalui jalur udara, jarak tempuh yang tidak terlalu jauh dari jantung Kabupaten Banyuwangi serta tempat-tempat pelayanan publik lainnya seperti Puskesmas, pasar tradisional dan tempat-tempat ibadah. Pantai ini dulunya dikenal dengan nama Banyualit yang kemudian diganti menjadi Pantai Blimbingsari pada tahun 1960-an. Pihak pengelola juga telah menambah sarana dan prasarana penunjang wisata seperti perbaikan toilet umum dan tempat bilas, pengadaan penyewaan kuda di bibir pantai dan perbaikan tembok di sepanjang garis pantai. Perbaikan sarana dan prasarana ini tidak lain adalah untuk menambah kenyamanan wisatawan saat berkunjung dan 
memberikan rasa aman.

Potensi yang dimiliki Pantai Blimbingsari belum dimaksimalkan seutuhnya. Selain panorama lautnya yang memukau, potensi lain yang dapat diulik dari pantai ini adalah potensi kuliner lautnya. Bahkan, popularitas kuliner ini boleh dibilang khas dan dapat dikategorikan sebagai ikon. Potensi kuliner yang tersedia di kawasan Pantai Blimbingsari meliputi ikan bakar dan beberapa olahan laut lainnya. Dengan adanya potensi kuliner ini, peningkatan kunjungan wisatawan di Pantai Blimbingsari pun turut meningkat dan menambah pemasukan masyarakat sekitar. Aktivitas kuliner ini terus berlangsung selama bertahun-tahun dan memperkuat brand Pantai Blimbingsari sebagai sentra kuliner ikan bakar di Banyuwangi. Tetapi hingga saat ini, brand identity yang dimiliki oleh Pantai Blimbingsari belum dapat dikatakan maksimal. Pengembangan kuliner ikan bakar sebagai ikon dari Pantai Blimbingsari pun belum dipatenkan dan penataan kedai-kedai di sepanjang garis pantainya belum rapi sehingga perlu adanya pengelolaan ulang dalam mengembangkan potensi Pantai Blimbingsari. Selain itu, meski Pantai Blimbingsari cukup populer dengan ciri khas ikan bakarnya dan lokasinya yang relatif dekat dengan Bandar Udara Banyuwangi, wisatawan dari kota lain belum mengenal baik destinasi ini. Brand ikan bakar yang melekat dengan jati diri Pantai Blimbingsari pun masih belum dikenal luas sehingga keunikan identitas ini perlu lebih diperkuat lagi.

Menurut Siagian (2014), strategi merupakan serangkaian keputusan atau tindakan mendasar yang disusun oleh manajemen puncak dan diimplementasikan oleh seluruh jajaran suatu organisasi dalam rangka pencapaian tujuan organisasi tersebut. Arseculeratne dan Yazdanifard (2014) menjelaskan bahwa brand strategy adalah bagian dari konsep brand management, sebagaimana untuk merealisasikan pengembangan terhadap produk, tempat dibutuhkan manajemen pemasaran yang terdiri perencanaan, analisis, strategi, pembangunan dan audit brand. Dalam penelitian ini, digunakan strategi dan brand strategy untuk memutuskan tindakan- tindakan selanjutnya agar dapat diimplementasikan dalam merumuskan strategi destination branding. Destination branding juga didefinisikan sebagai, nama, simbol, logo, word mark atau gambaran lainnya yang dapat mengidentifikasikan dan membedakan sebuah destinasi; selebihnya, menjanjikan sebuah pengalaman wisata yang dapat diingat karena keunikan yang dimiliki oleh sebuah destinasi; yang juga berfungsi dalam memperkuat ingatan, kenangan yang mengesankan dari sebuah pengalaman destinasi (Ritchie and Ritchi, 1998).

Studi menunjukkan bahwa destination branding lebih berkonsentrasi pada bagaimana pesan dan image dari destinasi tersebut diformulasikan dan diperlihatkan (Konecnik dan Gartner, 2007). Dengan demikian, strategi dalam destination branding haruslah mengusung ciri khas dan diferensiasi yang dimiliki oleh sebuah destinasi sehingga label tersebut dapat melekat di benak masyarakat (Ermilova \& Andreeva, 2017). Penyusunan strateginya pun harus disesuaikan dengan kondisi lapangan agar proses pengimplementasiannya dapat berjalan dengan sistematis (Huo, 2017).

\section{Metodologi}

Penelitian ini bertujuan untuk mencari strategi alternatif dalam melakukan destination branding di Pantai Blimbingsari yang dianalisa menggunakan pendekatan deskriptif kualitatif melalui analisis SWOT. Metode deskriptif kualitatif merupakan sebuah metode pengumpulan data yang dilakukan untuk menjawab permasalahan yang ada dengan metode pendekatan studi kasus. Metode deskriptif ini bertujuan menjelaskan fakta dan populasi dari suatu permasalahan tertentu pada perusahaan atau organisasi atau lingkungan secara faktual dan sistematis (Sugiyono, 2016).

Data yang digunakan dalam penelitian ini, dikelompokkan menjadi data primer dan data sekunder. Data primer merupakan data yang diperoleh secara langsung dalam penelitian melalui wawancara. Teknik wawancara yang dipilih adalah indepht interview (wawancara mendalam) 
kepada pengusaha warung ikan bakar di pantai Blimbingsari, Dinas Kebudayaan dan Pariwisata kabupaten Banyuwangi, akademisi, dan wisatawan. Keempat nara sumber tersebut dipilih dengan alasan bahwa mengerti dan terlibat langsung dalam kegiatan destination branding di Pantai Blimbingsari. Sementara itu, data sekunder merupakan data yang diperoleh melalui studi literatur.

Tahapan dalam analisis SWOT meliputi: tahap pengumpulan data, analisis data dan yang terakhir adalah tahapan pengambilan keputusan. Tahapan tersebut berupaya untuk menganalisis faktor internal (kekuatan dan kelemahan) serta faktor eksternal (peluang dan ancaman) dalam bentuk matrik IFE dan EFE. Menghitung bobot dan rating masing-masing faktor dan kemudian menampilkan dalam bentuk matriks IE. Menurut Rangkuti (2016), matriks SWOT dapatmenggambarkan secara jelas bagaimana peluang dan ancaman eksternal yang dihadapi perusahaan dapat disesuaikan dengan kekuatan dan kelemahan yang dimiliki. Menurut Chan (2011), analisis SWOT menggunakan kekuatan untuk mengatasi kelemahan dan untuk mengambil keuntungan dari setiap peluang sambil menghapus semua ancaman sehingga manajemen mendapatkan berbagai alternatif strategi. Berdasarkan matriks IE dibuat strategi alternatif yang dapat digunakan dalam pengembangan Pantai Blimbinsari sebagai Destination Branding sentra kuliner ikan bakar di Banyuwangi. strategi ditetapkan dengan maksud memanfaatkan kekuatan internal dan mengatasi kelemahan (David, 2008).

\section{Hasil dan Pembahasan}

\subsection{Evaluasi Faktor Internal}

Mengevaluasi faktor internal dilakukan dengan menghitung rata-rata skor tertimbang masingmasing faktor internal yang selanjutnya disusun dalam sebuah matriks evaluasi masingmasing faktor. Pada matriks evaluasi tersebut, pembobotan masing-masing faktor kekuatan dan kelemahan menggunakan metode pembobotan paired comparison. Kemudian digunakan matriks Internal Factor Evaluation (IFE) untuk melihat keadaan internal wisata kuliner ikan bakar pantai Blimbingsari. Adapun hasil analisis IFE dapat dilihat pada Tabel 1.

Tabel 1. Matriks IFE Pantai Blimbingsari

\begin{tabular}{|c|c|c|c|c|}
\hline \multicolumn{5}{|c|}{ FAKTOR INTERNAL } \\
\hline NO & KEKUATAN & BOBOT & RATING & SKOR \\
\hline 1 & Lokasi yang strategis & 0.0997 & 4 & 0.399 \\
\hline 2 & Citra kuliner ikan bakar yang melekat & 0.0796 & 4 & 0.318 \\
\hline 3 & Aksesibilitas yang mudah & 0.0871 & 4 & 0.348 \\
\hline 4 & Harga relatif terjangkau & 0.0906 & 3 & 0.272 \\
\hline 5 & Suasana yang nyaman & 0.0831 & 4 & 0.332 \\
\hline 6 & Memiliki atraksi wisata yang family friendly & 0.0934 & 3 & 0.280 \\
\hline 7 & Penggunaan bahan yang berasal dari pedagang lokal & 0.0823 & 4 & 0.329 \\
\hline \multicolumn{4}{|c|}{ TOTAL } & 2.279 \\
\hline NO & KELEMAHAN & BOBOT & RATING & SKOR \\
\hline 1 & $\begin{array}{l}\text { Belum adanya billboard atau ikon destinasi di titik- } \\
\text { titik yang potensial }\end{array}$ & 0.096 & 1 & 0.096 \\
\hline 2 & $\begin{array}{l}\text { Belum adanya tagline yang merefleksikan citra } \\
\text { destinasi }\end{array}$ & 0.097 & 1 & 0.097 \\
\hline 3 & Promosi belum maksimal & 0.079 & 1 & 0.079 \\
\hline 4 & $\begin{array}{l}\text { Belum adanya adanya standarisasi higienitas bagi } \\
\text { Pedagang }\end{array}$ & 0.057 & 1 & 0.057 \\
\hline 5 & Penggunaan alat-alat saji yang kurang layak & 0.055 & 1 & 0.055 \\
\hline \multicolumn{4}{|c|}{ TOTAL } & 0.384 \\
\hline \multicolumn{4}{|c|}{ TOTAL FAKTOR INTERNAL } & 2.663 \\
\hline
\end{tabular}


Berdasarkan Tabel 1, diketahui bahwa faktor internal yang paling dominan dalam branding Pantai Blimbiingsari adalah lokasinya yang strategis dengan skor 0.399. Dengan demikian, dapat disimpulkan bahwa lokasi menjadi salah satu kekuatan yang menunjang proses peningkatan branding. Sedangkan kelemahan terbesarnya adalah penggunaan alat-alat saji yang kurang layak, karena pada era new normal tourism ini, faktor kebersihan dan higinitas menjadi penentu utama baik buruknya sebuah brand atau citra destinasi (skor 0.057). Hasil analisis menghasilkan total skor tertimbang sebesar 2,663. Hal ini menunjukkan bahwa kemampuan faktor internal wisata kuliner pantai Blimbingsari dalam pengembangan sentrra kuliner ikan bakar berada pada posisi diatas rata-rata. Hal ini menunjukkan bahwa faktor kekuatan wisata kuiner ikan bakar pantai Blimbingsari lebih dominan dibandingkan faktor kelemahannya.

\subsection{Evaluasi Faktor Eksternal}

Mengevaluasi faktor eksternal dilakukan dengan menghitung rata-rata skor tertimbang masingmasing faktor kunci eksternal yang selanjutnya disusun dalam sebuah matriks evaluasi masing-masing faktor. Pada matriks evaluasi tersebut, pembobotan masing-masing faktor peluang dan ancaman menggunakan metode pembobotan paired comparison. Kemudian digunakan matriks External Factor Evaluation (EFE) untuk melihat keadaan eksternal wisata kuliner ikan bakar pantai Blimbingsari. Adapun hasil analisis IFE dapat dilihat pada Tabel 2.

Tabel 2. Matriks EFE Pantai Blimbingsari

\begin{tabular}{|c|c|c|c|c|}
\hline \multicolumn{5}{|c|}{$\begin{array}{l}\text { FAKTOR EKSTERNAL } \\
\end{array}$} \\
\hline No & PELUANG & BOBOT & RATING & SKOR \\
\hline 1 & $\begin{array}{l}\text { Peningkatan wisatawan melalui Bandar Udara } \\
\text { Banyuwangi }\end{array}$ & 0.145 & 3 & 0.435 \\
\hline 2 & $\begin{array}{l}\text { Sinergi dengan masyarakat lokal untuk meningkatkan } \\
\text { profit daerah }\end{array}$ & 0.145 & 4 & 0.580 \\
\hline 3 & Event kuliner dalam Banyuwangi Festival & 0.167 & 2 & 0.335 \\
\hline & TOTAL & & & 1.349 \\
\hline NO & ANCAMAN & BOBOT & RATING & SKOR \\
\hline 1 & Munculnya kompetitor baru & 0.192 & 3 & 0.576 \\
\hline 2 & Bencana alam dan pandemi & 0.118 & 1 & 0.118 \\
\hline 3 & Kurangnya kebersihan area pantai & 0.112 & 2 & 0.224 \\
\hline 4 & Kurangnya safety and security & 0.120 & 2 & 0.241 \\
\hline & TOTAL & & & 1.159 \\
\hline & TOTAL FAKTOR EKSTERNAL & & & 2.508 \\
\hline
\end{tabular}

Tabel 2 menunukkan bahwa fator peluang tertinggi adalah sinergi antar masyarakat untuk menciptakan siklus yang saling menguntungkan. Poin dari varibel ini mencapai 0.580 sehingga dengan adanya strategi yang tepat, optimalisasi peluang ini dapat meningkatkan destination branding yang berpengaruh positif bagi Pantai Blimbingsari dan meningkatkan brand image yang dimilikinya. Sedangkan ancaman tertingginya adalah kemunculan kompetitor baru dengan skor 0.576. Dapat disimpulkan bahwa kompetitor yang menyediakan suguhan dan potensi wisata serupa dapat menggusur citra destinasi yang selama ini dibentuk. Perlu adanya strategi khusus yang bersifat multiguna sehingga selain meningkatkan dan mempertahankan branding pada destinasi, juga meningkatkan minat kunjung wisatawan. Hasil analisis menghasilkan total skor tertimbang sebesar 2,508. Hal ini menunjukkan bahwa kemampuan faktor eksternal wisata kuliner pantai Blimbingsari dalam pengembangan sentrra kuliner ikan bakar berada pada posisi diatas rata-rata. Hal ini menunjukkan bahwa faktor peluang wisata kuiner ikan bakar pantai Blimbingsari lebih dominan dibandingkan faktor ancamannya. 


\subsection{Analisis Posisi Pengembangan}

Matriks IFE dan EFE yang telah diberikan bobot dan peringkat serta telah memiliki skor rata-rata tertimbang, kemudian akan digabung pada matriks internal dan eksternal. Skor bobot IFE pada sumbu X dan skor bobot EFE total pada sumbu Y. Matriks ini bermanfaat untuk mengetahui posisi pengembangan destinasi sehingga dapat digunakan untuk menetapkan strategi yang sesuai dijalankan perusahaan.

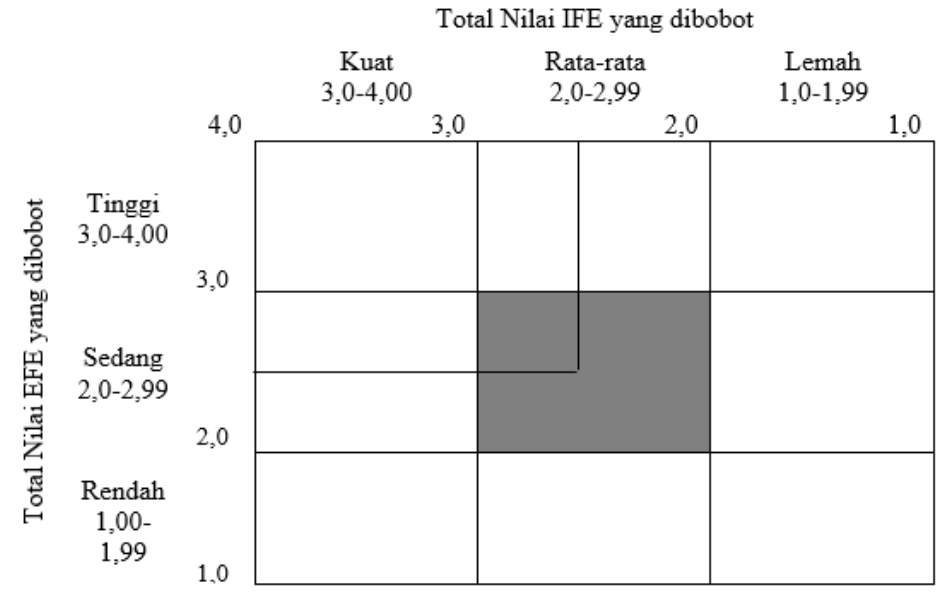

Gambar 1. Posisi Pantai Blimbingsari dalam Matriks IE

Posisi pada matriks IE (Gambar 1) menunjukan bahwa destinasi Pantai Blimbingsari berada di posisi internal dan eksternal yang cukup tinggi. Matriks IE berada dalam sel lima dengan dengan tipe Growth and Stability dimana perumusan strategi dihasilkan dari optimalisasi dan maintenance strategi yang telah dilakukan serta menciptakan strategi-strategi baru yang selaras dan sesuai dengan kondisi lapangan

\subsection{Perumusan Alternatif Strategi}

Berdasarkan analisis matriks Internal Eksternal (IE) di atas maka diperlukan perumusan aternatif strategi untuk mengetahui strategi branding untuk destinasi Pantai Blimbingsari sebagai sentra kuliner ikan bakar di Kabupaten Banyuwangi. Berikut ini gambaran matriks SWOT pada Gambar 2.

Menurut David dan Wheelen (2003) Matriks SWOT menggambarkan bagaimana manajemen dapat mencocokkan peluang-peluang dan ancaman-ancaman eksternal yang dihadapi suatu perusahaan tertentu dengan kekuatan dan kelemahan internalnya, untuk menghasilkan empat rangkaian alternatif strategis. Dengan demikian, dapat diketahui bahwa matriks SWOT digunakan sebagai alat dalam merumuskan keempat strategi. Keempat strategi tersebut adalah strategi SO (Strenght-Opportunity), strategi WO (Weakness - Opportunity), strategi ST (Strenght - Threat) dan strategi WT (Weakness - Threat). Berdasarkan analisis matriks SWOT, penelitian ini menghasilkan 11 strategi. Namun, peneliti hanya memilih lima strategi yang dinilai lebih penting dan cocok untuk diterapkan di Pantai Blimbingsari sebagai strategi branding serta sesuai dengan pertimbangan dari analisis proses pengembangan destinasi. Berikut kelima strategi tersebut: 


\begin{tabular}{|c|c|c|}
\hline Faktor Eksternal & $\begin{aligned} & \text { Strengths }(\mathbf{S}) \\
& \text { 1. } \text { Lokasi yang strategis } \\
& \text { 2. } \text { Citra kuliner ikan bakar yang melekat } \\
& \text { 3. } \text { Aksesibilitas yang mudah } \\
& \text { 4. } \text { Harga relatif terjangkau } \\
& \text { 5. } \text { Suasana yang nyaman } \\
& \text { 6. } \text { Memiliki atraksi wisata yang family friendly } \\
& \text { 7. } \text { Penggunaan bahan yang berasal dari } \\
& \text { pedagang lokal }\end{aligned}$ & 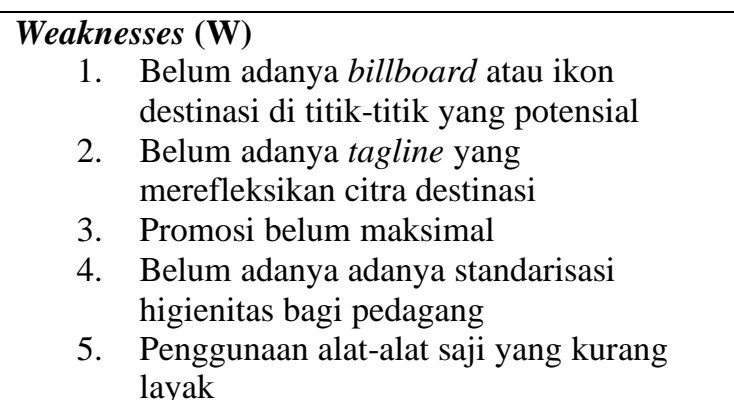 \\
\hline $\begin{aligned} & \text { Opportunities }(\mathbf{O}) \\
& \text { 1. } \text { Peningkatan wisatawan melalui } \\
& \text { Bandar Udara Banyuwangi } \\
& \text { 2. } \text { Sinergi dengan masyarakat lokal } \\
& \text { untuk meningkatkan profit daerah } \\
& \text { 3. } \text { Event kuliner dalam } \\
& \text { Banyuwangi Festival }\end{aligned}$ & 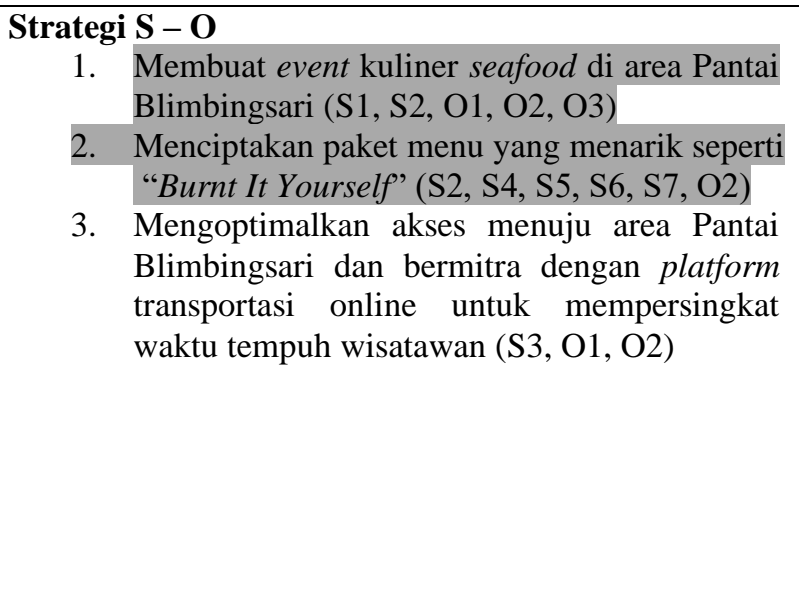 & $\begin{array}{l}\text { Strategi W-O } \\
\text { 1. Memasang pamflet atau billboard dengan } \\
\text { tagline yang menarik di lokasi yang } \\
\text { strategis (W1, W2, W3, O1) } \\
\text { 2. Bekerja sama dengan Bandara } \\
\text { Banyuwangi dan travel agent untuk } \\
\text { mempromosikan kuliner ikan bakar Pantai } \\
\text { Blimbingsari (W3, O1, O2) } \\
\text { 3. Menjalin mitra dengan Dinas Kesehatan } \\
\text { dan LSM untuk memberikan pelatihan } \\
\text { sanitasi dan kebersihan pangan (W4, W5, } \\
\text { O2) } \\
\text { 4. Meningkatka brand image dengan meng- } \\
\text { endorse influencer untuk } \\
\text { meningkatkan promosi (W3, O2) }\end{array}$ \\
\hline $\begin{array}{cl}\text { Threats } & (\mathbf{T}) \\
\text { 1. } & \text { Munculnya kompetitor baru } \\
\text { 2. } & \text { Bencana alam dan pandemi } \\
\text { 3. } & \text { Kurangnya kebersihan area pantai } \\
\text { 4. } & \text { Kurangnya safety and security }\end{array}$ & 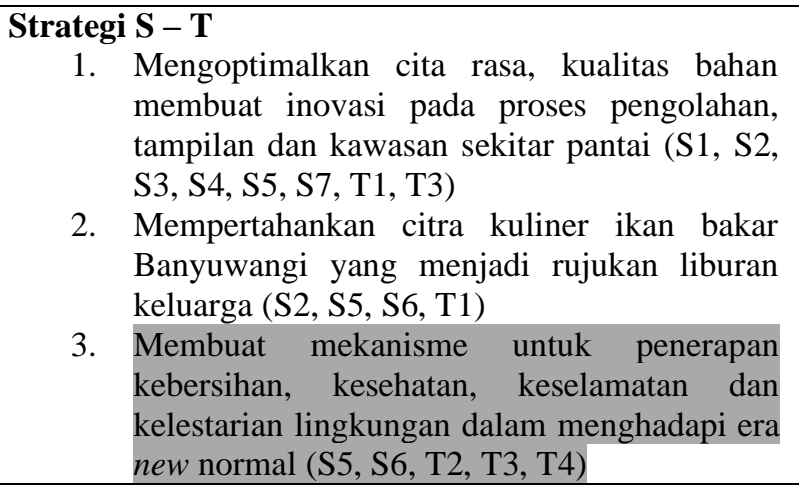 & $\begin{array}{l}\text { Strategi } \mathbf{W}-\mathbf{T} \\
\text { 1. } \\
\text { Bekerja sama dengan platform pembelian } \\
\text { makanan online dan mempromosikan } \\
\text { produk melalui influencer maupun media } \\
\text { sosial (W1, W2, W3, W4, W5, T1, T2, T3, } \\
\text { T4) }\end{array}$ \\
\hline
\end{tabular}

Gambar 2. Perumusan alternative strategi dalam Matriks SWOT 
1. Membuat event kuliner seafood di area Pantai Blimbingsari

Banyuwangi memiliki beragam event kuliner yang dituangkan dalam agenda Banyuwangi Festival atau B-Fest, dan beberapa diantaranya adalah kuliner hasil olahan laut atau seafood. Dengan membuat event serupa di Pantai Blimbingsari, maka brand image pantai ini sebagai rujukan kuliner ikan bakar semakin tinggi. Event-event yang sangat potensial dikembangkan di kawasan Pantai Blimbingsari dapat berupa event tahunan yang tertuang dalam B-Fest seperti pada ritual adat Petik Laut, maupun agenda regular yang diadakan setiap minggu mengingat jumlah wisatawan yang berkunjung mencapai 1000 orang.

Selain menarik, event yang digelar pun harus memiliki diferensiasi dari event-event seafood lainnya. Inovasi dari pedagang dan pengelola sangat dibutuhkan agar event tersebut terus berkelanjutan dan menjadi salah saturujukan liburan keluarga. Inovasi yang diciptakan dapat berupa variasi olahan ikan bakar, pengadaan undian maupun voucher menarik serta tampilan stand booth atau tempat display yang unik dan menarik.

\section{Menciptakan menu paket yang menarik seperti "Burnt It Yourself"}

Hingga saat ini, menu hidangan yang disediakan oleh pedagang ikan bakar di Pantai Blimbingsari masih terbilang monoton. Tidak ada diversifikasi produk atau paket-paket khusus yang ditawarkan pada wisatawan. Padahal, dengan adanya menu paket yang unik, wisatawan akan semakin betah dan tidak ragu untuk kembali berkunjung. Contoh paket yang dapat dijadikan referensi adalah paket Membakar Sendiri atau "Burnt It Yourself'. Wisatawan dapat memilih ikan sesuai dengan keinginannya, kemudian proses membakar akan dilakukan secara mandiri. Pedagang akan menyiapkan alat pembakaran, alat makan, bumbu dan ikan segar untuk selanjutnya akan diolah sendiri (dibakar) oleh wisatawan dengan tingkat kematangan sesuai selera. Sehingga, wisatawan tidak hanya menunggu makanannya siap, melainkan juga turut mengolah hidangannya sendiri, mendapatkan pengalaman grilling yang tidak didapatkan di destinasi lainnya serta dapat mendokumentasikan prosesnya. Dalam paket ini, point of interest yang menarik bagi wisatawan adalah pengalaman membakar ikan sendiri bersama keluarga dan kolega terdekat. Atmosfir yang diciptakan pada momen ini tentu menambah daya tarik dan pembeda dengan destinasi yang menawarkan kuliner yang sama. Di samping menciptakan menu paket yang variatif, melakukan maintenance, optimalisasi terhadap kualitas rasa dan inovasi juga menjadi poin penunjang yang mampu meningkatkan loyalitas wisatawan. Cita rasa kualitas dan mutu produk ikan bakar menjadi ujung tombak dalam sebuah branding produk atau destinasi kuliner. Semakin inovatif hidangan ikan bakar yang disajikan, maka semakin banyak wisatawan yang tertarik untuk mencicipi produk ikan bakar yang ditawarkan. Dengan demikian, branding kuliner ikan bakar yang khas dan inovatif semakin terbentuk di Pantai Blimbingsari.

3. Bekerja sama dengan Bandara Banyuwangi dan travel agent untuk mempromosikan kuliner ikan bakar Pantai Blimbingsari

Menjalin kemitraan dengan bandara menjadi salah satu langkah yang tepat mengingat lokasi Pantai Blimbingsari yang berdekatan. Kerja sama ini bisa dilakukan untuk pemasangan pamflet atau billboard di area internal bandara sehingga memudahkan proses branding Pantai Blimbingsari sebagai salah satu destinasi unggulan kuliner ikan bakar di Banyuwangi, bahkan perintis warung lesehan ikan bakar. Tidak hanya itu, pemasangan media visual dengan tagline yang menarik bisa dilakukan di dalam bangunan bandara, tempat wisatawan pertama kali mendarat seperti di area pengambilan bagasi. Wisatawan dapat melihat produk kuliner ikan bakar di Pantai Blimbingsari dan dengan demikian, muncul ketertarikan untuk meninjau ulang dan mencicipi produk kulinernya. Secara tidak langsung, aktivitas pengenalan produk destinasi semacam ini dapat membangun perspektif wisatawan dan meningkatkan citra kuliner ikan bakar itu sendiri.

Selain itu, kerja sama yang sangat diperlukan untuk membangun kembali citra kuliner 
pantai ini adalah kemitraan dengan travel agent sebagai penyedia perjalanan wisata dengan menyelipkan kunjungan di Pantai Blimbingsari dalam itinerary perjalanan wisata agar wisatawan dapat merasakan cita rasa kuliner seafood Banyuwangi, terutama ikan bakarnya. Pihak travel agent juga akan mendapatkan diskon atau harga khusus dari pedagang ikan bakar sehingga harga jual yang diberikan menjadi jauh lebih murah. Langkah ini tidak hanya mampu meningkatkan jumlah kunjungan wisatawan, melainkan membangun perspektif dan citra kuliner yang dampak positifnya akan meluas dalam pengembangan Pantai Blimbingsari sendiri.

4. Membuat mekanisme untuk penerapan kebersihan, kesehatan, keselamatan dan kelestarian lingkungan dalam menghadapi era new normal.

Saat ini, kebersihan, kesehatan, keselamatan dan kelestarian lingkungan menjadi prioritas dalam industri pariwisata, terutama di bidang kuliner. Wisatawan akan semakin waspada dan lebih selektif dalam memilah tempat makan dan produk makanan yang dihidangkan. Baik dari tempat makan, alat-alat produksi dan alat-alat saji serta kualitas bahan makanan yang akan diolah. Pihak pengelola dapat berkolaborasi dengan lembaga-lembaga yang menaungi masalah kebersihan dan sanitasi seperti Dinas Kesehatan dan BPOM untuk menciptakan standarisasi dan SOP yang dapat langsung diterapkan di Pantai Blimbingsari. Optimalisasi dalam merespon dampak pandemi menjadi sebuah langkah yang harus diperhatikan dengan seksama dan memerlukan sinergi dari seluruh stakeholder terkait. Perlu adanya edukasi dan pembaruan SOP terhadap sanitasI alat-alat makan dan prosedur ketika memasuki kawasan Pantai Blimbingsari sendiri. Misalnya saja, ditambahkan fasilitas alat pengecekan suhu badan dan wisatawan yang masuk akan disemprot dengan hand sanitizer. Langkah lain yang tidak kalah penting adalah pengecekan kondisi kebersihan bahan-bahan makanan secara berkala. Dengan adanya SOP, pedagang dapat memilah dan memilih bahanbahan yang sesuai dengan kebutuhan. Sterilisasi alat-alat yang digunakan juga menjadi langkah penting untuk kian meningkatkan nilai jual produk makanan. Wisatawan pun dapat lebih nyaman dengan adanya standar serta SOP baru yang lebih menjamin mutu dan kualitas produk.

Namun, perlu adanya peninjauan ulang pasca pemberian SOP dan standar baru dari lembaga-lembaga terkait dengan pengawasan dan pembinaan lanjutan agar pedagang ikan bakar dan pengelola dapat terus melakukan aktivitas new normal secara berkelanjutan. Output dari adanya pengawasan dan pembinaan ini adalah adanya peningkatan mutu dan kualitas produk kuliner secara signifikan yang nantinya akan meningkatkan tingkat kunjungan wisatawan.

5. Bekerja sama dengan platform pembelian makanan online dan mempromosikan produk melalui influencer maupun media sosial

Selain melakukan kerja sama dengan supplier bahan-bahan pokok, melakukan kemitraan dengan platform pembelian makanan online juga menjadi langkah yang tepat di era digital ini. Pengelola Pantai Blimbingsari dan layanan pembelian makanan online dapat menjalin hubungan yang saling menguntungkan dengan bertambahnya jumlah wisatawan yang berkunjung atau peningkatan citra destinasi. Strategi yang dapat ditempuh misalnya pemberian potongan harga atau reward khusus yang didapakan konsumen ketika melakukan pembelian secara berkala seperti voucher belanja ikan bakar atau gratis ongkos kirim.

Tidak hanya kerja sama dengan pembelian makanan online yang meningkatkan branding kuliner ikan bakar di Pantai Blimbingsari. Melakukan endorsement dengan influencer yang memiliki banyak pengikut di media sosial juga menjadi strategi yang cukup jitu untuk meningkatkan awareness dan brand image. Endorsement melalui influencer menjadi pilihan banyak orang untuk memperkenalkan produk serta meningkatkan branding produk. Influencer dapat me-repost produk kuliner ikan bakar yang disajikan pedagang di Pantai Blimbingsari dan 
memberikan ulasan positif sehingga wisatawan yang menjadi pengikut sosial medianya akan lebih tertarik untuk menjajal makanan serupa. Brand image yang muncul pasca endorsement pun akan semakin merekatkan citra kuliner ikan bakar Banyuwangi dengan Pantai Blimbingsari. Dengan demikian, citra kuliner ikan bakar kian terbentuk. Influencer yang terlibat dalam proses branding dan promosi ini tidak hanya terikat pada perseorangan, melainkan juga lembaga dan perusahaan. Misalnya saja PT. Angkasa Pura sebagai penyedia layanan transportasi udara yang digdaya, tentu dapat mempengaruhi pengguna jasa layanannya dengan lebihbaik. Seperti menayangkan video suasana di Pantai Blimbingsari di pesawat yang akan turun di Banyuwangi, atau memasang pamflet di dalam bangunan bandara untuk semakin meningkatkan brand awareness wisatawan.

\section{Kesimpulan}

Pantai Blimbingsari merupakan perintis warung ikan bakar berbasis lesehan di Banyuwangi dan brand kuliner ikan bakarnya pun menjadi andalan untuk menarik minat kunjung wisatawan selama bertahun-tahun. Dengan branding yang tepat, citra kuliner ini menjadi potensi yang kuat untuk dikembangkan secara lanjutan. Potensi kuliner ikan bakarnya sendiri terdiri dari citra dan perspektif wisatawan yang telah terbentuk sejak lama, cita rasa yang lezat, harga terjangkau serta memiliki suasana warung yang nyaman.

Faktor kekuatan yang paling dominan dimiliki oleh Pantai Blimbingsari adalah lokasinya yang strategis dan faktor kelemahan yang utama adalah penggunaan alat-alat saji yang kurag layak. Faktor peluang tertinggi adalah sinergi dengan masyarakat lokal untuk meningkatkan profit daerah dan faktor ancaman utamanya adalah kemunculan kompetitor baru.

Alternatif strategi yang diformulasikan untuk Destination Branding di Pantai Blimbingsari adalah membuat event kuliner seafood di area Pantai Blimbingsari, menciptakan menu paket yang menarik seperti "Burnt It Yourself", bekerja sama dengan Bandara Banyuwangi dan travel agent untuk mempromosikan kuliner ikan bakar Pantai Blimbingsari, menciptakan SOP pada sanitasi, cara makan dan entrance gate dalam respon menghadapi era new normal, bekerja sama dengan platform pembelian makanan online dan mempromosikan produk melalui influencer maupun media sosial.

\section{Saran}

Diperlukan adanya penelitian lebih lanjut untuk menyusun prioritas strategi dan menyusun langkah teknis dengan meilbatkan semua pemangku kepentingan yang terlibat.

\section{Ucapan Terimakasih}

Penelitian ini didanai oleh DIPA Politeknik Negeri Banyuwangi Tahun Anggaran 2020 dengan kontrak No. 2406.16/PL36/PT.01.03/2020. Terimakasih kami sampaikan kepada Pusat Penelitian dan Pengabdian kepada Masyarakat Politeknik Negeri Banyuwangi atas dukungan dana yang diberikan sehingga penelitian ini bisa terlaksana. Terima kasih juga kami sampaikan kepada semua narasumber yang telah membantu dalam pelaksanaan penelitian ini.

\section{Daftar Pustaka}

Arseculeratne, D., and Yazdanifard, R. (2014). How Green Marketing Can Create A Sustainable Competitive Advantage for A Business. International Business Research. 7(1): 130-137.

Chan, X. (2011). A SWOT Study of The Development Strategy of Haier Group as One of The Most Successful Chinese Enterprises. International Journal of Business and Social Science. 2(11) : $147-153$

David F.R. (2012). Manajemen Stretegis: Konsep. Salemba Empat. Jakarta.

Ermilova, M. dan Andreeva , E. (2017). Destination Branding as A Tool for Sustainable Tourism Development. Journal of Tourism, Heritage \& Services Marketing. 3(1): 9-17.

Huo, Y. (2017). The Management of Destination Branding: Applying Tourist-Based Brand Equity to Utah as A Tourist Destination. Journal of Tourism and Hospitality Management. 5(2): 101-109. 
Konecnik Maja., Garrtnet, W.C. (2007). Customer-Based Brand Equity for a Destination. Annals of Tourim Research. 34(2): 400-421.

Rangkuti, F. (2016). Teknik Membedah Kasus Bisnis Analisis SWOT . Jakarta : PT Gramedia.

Ritchie, J. R. Brent , and Robin J. B. Ritchie (1998). "The Branding of Tourism Destinations: Past Achievements and Future Challenges". Proceedings of the 1998 Annual Congress of the International Association of Scientific Experts in Tourism, Destination Marketing: Scopes and Limitations, edited by Peter Keller. Marrakech, Morocco: International Association of Scientific Experts in Tourism, 89-116

Siagian, Sondang P. (2004). Manajemen Strategik. Jakarta: PT. Bumi Aksara

Sugiyono. (2016). Metode Penelitian Kuantitatif, Kualitatif dan R\&D. Bandung: Alfabeta. 